\title{
SIMPLE VIEWS ON CONDENSED MATTER
}


This page is intentionally left blank 


\section{SIMPLE}
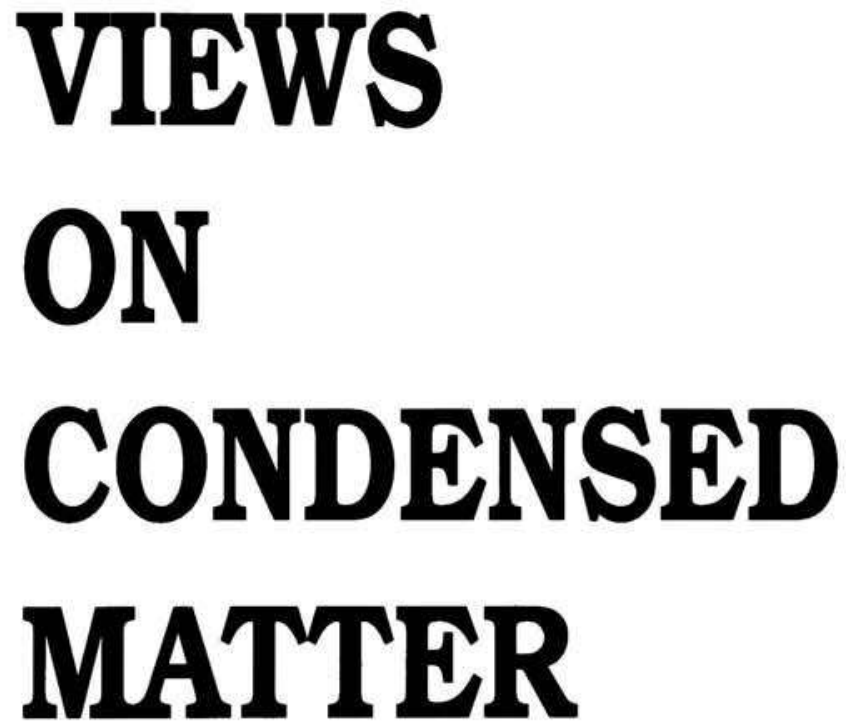

\section{Pierre-Gilles de Gennes}

Collège de France 
Published by

World Scientific Publishing Co. Pte. Ltd.

P O Box 128, Farrer Road, Singapore 9128

USA office: Suite 1B, 1060 Main Street, River Edge, NJ 07661

UK office: 73 Lynton Mead, Totteridge, London N20 8DH

The author and publisher would like to thank the following publishers of the various journals and books for their assistance and permission to include the selected reprints found in this volume:

Academie des Sciences, Institut de France (C. R. Acad. Sci. (Paris)); American Chemical Society (J. Phys. Chem., Maromolecules); American Institute of Physics (J. Chem. Phys.); American Physical Society (Phys. Rev., Rev. Mod. Phys.); CNRS Publications (De la Physique Theorique à la Biologie); Elsevier Science Publishers (Advances in Colloid and Interface Science, Phys. Lett.); IDSET, Paris (Symmetries and Broken Symmetries in Condensed Matter Physics); Indian Academy of Sciences (Pramana); Les Editions de Physique (Journal de Physique, J. Phys. Rad.); Pergamon Press (Solid State Comm.); Physics Publishing Co. (Physics); Royal Society of Chemistry (Faraday Discussions of the Royal Society of Chemistry); Societé Française de Chimie (J. Chim. Phys.); Società Italiana di Fisica (Rivista del Nuovo Cimento); Springer (Physics of Amphiphilic Layers).

Cover : Flying Apsara (China, 5th Century AD), sketch by P.G. de Gennes.

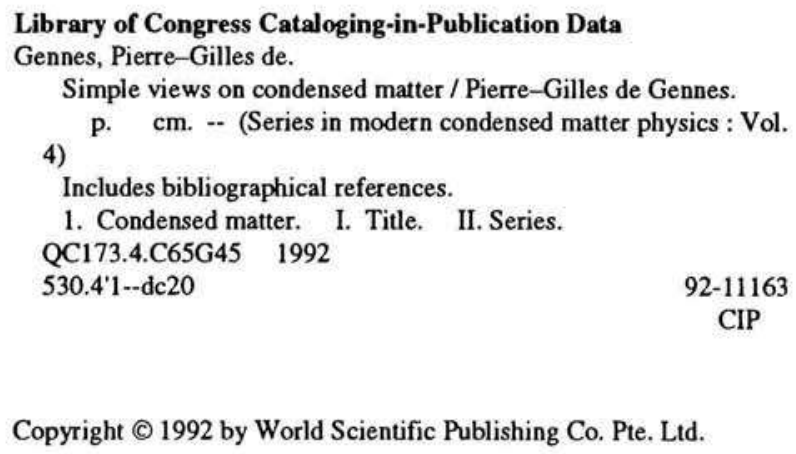

Printed in Singapore by Singapore National Printers Ltd. 


\section{Foreword}

Books of "collected papers" are frequent in our days. Are they useful? I am hesitant about this. Looking at my own articles, I found a number of ideas which ultimately lead to nowhere... . Also a certain fraction was wrong.

However, on closer scrutiny, I listed two lots which could still, possibly, be useful. The articles of the first lot are relatively general, but simple, and can be used as an elementary starting point for a beginner. The second lot is formed by papers which never really reached an international readership, because they appeared in relatively obscure journals. I was tempted to give them a second chance - but finally we took only a few (because of a language problem).

It rapidly became obvious that the articles in the list - being rather ancient - would give a distorted view of their own subfield, since science moves fast. It was necessary then to add some comments, or "afterthoughts". These afterthoughts are highly subjective! They sometimes focus on one later discovery, by younger colleagues, based on the same general ideas. Some other comments concern a flaw in my original views.

On the whole, I found it amusing to observe how short-sighted I have been — unable to imagine certain natural consequences of one idea. Some of these surprises are also described in the "afterthoughts". On the other hand, I never give a detailed list of references to more recent work. Only a few key references show up: I owe a lot here to Y. Heffer and M. Monnerie, who traced them. I am also thankful to the various publishers who allowed us to reprint the papers - with one exception (Gordon and Breach), where the permission fees for one article were at such a high cost, that we were forced to take this paper out of our list.

The whole construction is fragile. But I still hope that it can give, to a young reader, a certain feeling about the enthusiasm (and novelty) of our condensed matter research during these post war decades... .

Pierre Gilles de G.

Paris, March 1992 
This page is intentionally left blank 
Foreword

\section{Part I. Solid State}

1. Sur un exemple de propagation dans un milieu désordonné (with P. Lafore and J. P. Millot)

J. Phys. Rad. 20, 624 (1959)

2. Effects of double exchange in magnetic crystals Phys. Rev. 118, 141 (1960)

3. Nuclear magnetic resonance modes in magnetic material. I. Theory (with P. Pincus, F. Hartmann-Boutron, J. M. Winter)

Phys. Rev. 129, 1105 (1963)

4. Onset of superconductivity in decreasing fields

(with D. Saint-James)

Phys. Lett. 7, 306 (1963)

5. Boundary effects in superconductors

Rev. Mod. Phys. 36, 225 (1964)

\section{Part II. Liquid Crystals}

6. Soluble model for fibrous structures with steric constraints

J. Chem. Phys. 48, 2257 (1968)

7. Conjectures sur l'état smectique

J. de Phys. C4 30, 65 (1969)

8. Dynamics of fluctuations in nematic liquid crystals (with Groupe d'Etudes des Cristaux Liquides, Orsay)

J. Chem. Phys. 51, 816 (1969)

9. Note on the dynamics of prenematic fluids

(unpublished)

10. An analogy between superconductors and smectics A

Solid Stat. Comm. 10, 753 (1972)

11. Hydrodynamic properties of fluid lamellar phases of lipid/water (with F. Brochard)

Pramana, Supp. 1, 1 (1975) 


\section{Part III. Polymers}

12. Quasi-elastic scattering of neutrons by dilute, ideal, polymer solutions:

I. Free-draining limit

Physics 3, 37 (1967)

13. Quasi-elastic scattering by dilute, ideal, polymer solutions:

II. Effects of hydrodynamic interactions

(with E. Dubois-Violette)

Physics 3, 181 (1967)

14. Minimum number of aminoacids required to build up a specific receptor

with a folded polypeptide chain

Introduction to Polymer Dynamics (Cambridge Univ. Press, 1990), pp. 17-26

15. Reptation of a polymer chain in the presence of fixed obstacles

J. Chem. Phys. 55, 572 (1971)

16. Coil-stretch transition of dilute flexible polymers under ultrahigh

velocity gradients

J. Chem. Phys. 60, 5030 (1974)

17. Solutions of flexible polymers: neutron experiments and interpretation

(with M. Daoud, J. P. Cotton, B. Farnoux, G. Jannink, G. Sarma,

H. Benoit, R. Duplessix, C. Picot)

Macromolecules 8, 804 (1975)

18. Theoretical methods of polymer statstics

Rivista del Nuovo Cimento 7, 363 (1977)

19. Ecoulements viscométriques de polymères enchevêtrés

C. R. Acad. Sci. (Paris) 288, 219 (1979)

20. Theory of long-range correlations in polymer melts

Faraday Discussions of the Royal Society of Chemistry, no. 68, 96 (1979)

21. Tight knots

Macromolecules 17, 703 (1984)

22. A second type of phase separation in polymer solutions

C. R. Acad. Sci. (Paris) 313, 1117 (1991)

\section{Part IV. Interfaces}

23. Phénomènes aux parois dans un mélange binaire critique

(with M. E. Fisher)

C. R. Acad. Sci. (Paris) 287B, 207 (1978)

24. Suspensions colloïdales dans une solution de polymères

C. R. Acad. Sci. (Paris) 288B, 359 (1979)

25. Conformations of polymers attached to an interface

Macromolecules 13, 1069 (1980) 
26. Sur une règle de somme pour des chaînes polymériques semi-diluées près d'une paroi

C. R. Acad. Sci. (Paris) 290B, 509 (1980)

27. Microemulsions and the flexibility of oil/water interfaces

(with C. Taupin)

J. Phys. Chem. 86, 2294 (1982)

28. Transitions de monocouches à molécules polaires

(with D. Andelman, F. Brochard, J.-F. Joanny)

C. R. Acad. Sci. (Paris) 301, 675 (1985)

29. Polymers at an interface: a simplified view

Advances in Colloid and Interface Science 27, 189 (1987)

30. Stabilité des films de savon "jeunes"

C. R. Acad. Sci. (Paris) 305, 9 (1987)

\section{Part V. Wetting and Adhesion}

31. Wetting: statics and dynamics

Rev. Mod. Phys. 57, 827 (1985)

32. Dynamics of drying and film-thinning

Physics of Amphiphilic Layers, ed. J. Meunier, D. Langevin and N. Bocarra (Springer, 1987), p. 64

33. Tension superficielle des polymères fondus

C. R. Acad. Sci. (Paris) 307, 1841 (1988)

34. Etalement d'une goutte stratifiée incompressible

(with A. M. Cazabat)

C. R. Acad. Sci. (Paris) 310, 1601 (1990)

35. Dynamics of partial wetting

(with F. Brochard-Wyart)

Advances in Colloïd and Interface Science 39, 1 (1992)

36. Fracture d'un adhésif faiblement réticulé

C. R. Acad. Sci. (Paris) 307, 1949 (1988)

37. Polymer-polymer welding and sliding

(unpublished)

\section{Part VI. Chirality}

38. Sur l'impossibilité de certaines synthèses asymétriques

C. R. Acad. Sci. (Paris) 270B, 891 (1970) 
39. Pierre Curie et le role de la symétrie dans des lois physiques

Symmetrics and Broken Symmetries in Condensed Matter Physics, edited by N. Boccara (IDSET, 1981), pp. 1-9

40. Discrimination chirale dans une monocouche de Langmuir

C. R. Acad. Sci. (Paris) 307, 233 (1988) 